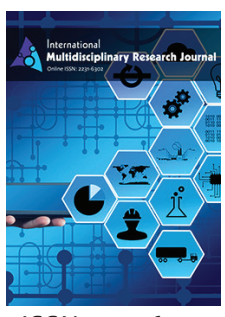

ISSN: $2231-6302$
Received: January 09,2020 Accepted: March 30,2020 Published: April 11, 2020

*Corresponding Author: Mohammad Hasan

Chowdhury

Email: mdhsnchowdhury@ gmail.com

\section{Rooftop gardening to improve food security in Dhaka city: A review of the present practices}

\author{
Mohammad Hasan Chowdhury ${ }^{1 *}$, Md. Fahim Sharker Eashat', \\ Chinmoy Sarkar', Nafisa Habib Purba', Mohammad Asadul Habib', \\ Plabon Sarkar', Lincon Chandra Shill'
}

'Department of Food Technology and Nutrition Science, Noakhali Science and Technology University, Sonapur, Noakhali-3814, Bangladesh, ${ }^{2}$ Technical Coordinator, CARE Bangladesh, Cox's Bazar-4750, Bangladesh

\begin{abstract}
In recent years, the trend of growing vegetables on green roofs has gained momentum as a way of promoting agricultural sustainability in Dhaka City. Rooftop gardens become an important part of urban agriculture's recent rejuvenation and offer alternative spaces for urban markets to grow vegetable products. Green roofs create spaces for vegetable crop production, thereby creating opportunities for agricultural incorporation into urban communities. At present, however, vegetable production activities on rooftops are limited due to multiple challenges that need to be addressed before widespread implementation takes place. Rooftop agriculture can improve various ecosystem services, enhance the biodiversity of urban areas and reduce food insecurity. Food production from green roofs will help support and sustain food for urban communities and provide a rare opportunity to grow food efficiently in typically unused spaces. As human populations become more urbanized and urban consumers become more interested in local food for their families, the use of alternative agricultural production systems, such as green roof technologies, will increase in importance. While cultivating food on buildings is a key component of making cities more sustainable and habitable, green roofs are not the total solution for providing cities with food security. They should be viewed more as a supplement to other sources of food production in urban areas.
\end{abstract}

KEYWORDS: Green roofs, food security, Bangladesh

\section{INTRODUCTION}

Bangladesh is regarded as a survivor of the adverse effects of climate change as one of the vulnerable countries. Throughout today's rapidly growing population, the country's leading development issues include poverty alleviation, sustainable development, food security, and environmental management. Whereas, being a densely populated city, Dhaka has surpassed its capacity to carry. In Bangladesh, the number of low-income consumers in cities is also increasing rapidly due to migration from rural areas to urban areas. Urban agriculture can provide a source of fresh produce for urban residents, a better diet, and substantial budgetary savings for households. Vegetated surfaces have important properties for sound insulation and are often used in urban settings for their potential for noise reduction. Green roofs can provide major incentives for buildings to reduce noise. It can also build jobs and economic facilities through its backward and forward relations. Bellows and Hamm (2003) claimed that a rooftop garden can complement the community's diets by providing fresh produce and a tangible benefit to food production. ${ }^{1}$ With rapid and unplanned urbanization, the incidence of urban deprivation and food insecurity has also increased alarmingly in Dhaka. ${ }^{2}$ Islam (2004) claimed that urban agriculture (UA) contributes to food security by increasing food supply and improving the quality of perishable food to urban consumers. He also indicated that strong political engagement and sound policy guidance are the preconditions for establishing a supportive environment for RTG. ${ }^{3}$ This study aims to identify potential for and obstacles to UA concerning to rooftop gardening (RTG) and to explore strategies for promoting food security in Dhaka.

\section{A. Definition of Green Roofs}

"Green roofs (also known as rooftop gardens, living roofs, and eco-roofs) are roofs of buildings covered with a growth substrate and plants such as trees, shrubs, bushes, and grass". ${ }^{4}$ Rooftop garden is a great way to enhance buildings in urban areas by landscaping that can turn obsolete areas into a productive area offering ecological and economic services. There is extensive use of rooftop gardens in Europe. One in

Copyright: (c) The authors. This article is open access and licensed under the terms of the Creative Commons Attribution License (http://creativecommons.org/licenses/by/4.0/) which permits unrestricted, use, distribution and reproduction in any medium, or format for any purpose, even commercially provided the work is properly cited. Attribution — You must give appropriate credit, provide a link to the license, and indicate if changes were made. 
ten apartment roofs in Germany, for instance, were greened in 1996, while in Switzerland about 70 percent of the apartment roof was greened. ${ }^{5}$

\section{B. Types of Green Roof}

There are two main types of comprehensive and intensive green roof systems. Extensive green roofs are lightweight, have a narrow range of plants and are built for low maintenance; these green roofs differ in soil depths of $5-15 \mathrm{~cm}$ (2-6 in) with a weight increase of 70-170kg / sq.ft (14-35 lb / sq.ft), typically consisting of mosses and herbs and are distinguished by low capital costs, high plant variety, and minimal maintenance needs. On the other hand, extensive green roofs have deep soils, a wide selection of plants, and are built for human recreational use. These have a soil depth ranging from $20-60 \mathrm{~cm}$ (8-24 in) with a saturated weight increase of 290-967.7 kg/sq. ft (60-200 $\mathrm{lb} / \mathrm{sq} . \mathrm{ft}$ ). The roofs are frequently accessible and characterized by increased weight and structural implications, elaborate irrigation, and drainage systems, increased plant diversity (trees and shrubs) and more maintenance needs. ${ }^{6}$

One of Dhaka City's known facts is its lack of open spaces that are required for socialization for its inhabitants. Nowadays, in some buildings in Dhaka city, many architects practice green roofs, although not very scientifically. For local plants in the roof and other elevated building plants, many of the buildings are maintaining for a long time. While green roofing practices in Dhaka apartment buildings are small, there is vast potential to incorporate green roofing concepts in Dhaka city context. ${ }^{6}$

It is possible to categorize green roof and roof gardening in Dhaka into four forms based on their use and appearance. ${ }^{7}$

A. Extensive green roofs

B. Extensive with some intensive plantation

C. Plants in fixed and designed pots 8

D. Plants in movable pots ${ }^{8}$

Intensive green roofs are uncommon in Dhaka practice. Type 'A', ' $\mathrm{B}$ ' and ' $\mathrm{C}$ ' are more generally constructed in the construction phase and these rooftops are regularly maintained. Typically the users grow Type 'D' roof gardens after the construction.

\section{METHODS AND MATERIALS}

The relevant information on the subject has been gathered from various primary and secondary sources. A questionnaire survey of household owners and a survey of residents and responsible authorities of selected public and commercial buildings investigated the viability of rooftop gardening (RTG). In addition, there was also a focus group discussion where participants were invited to discuss the city's rooftop gardening opportunities and issues. For example, NGO people (on providing microcredit), City Corporation Departments (on changing zoning regulation), land and house owners (on leasing and enabling tenants to garden) and the general public (on their overall reaction) were asked to express their opinion.

\section{RESULTS AND DISCUSSION}

Food production and consumption in urban areas has become a global concern due to the increasing number of people living in and moving to urbanized living spaces, which challenges food security. ${ }^{9}$ Rooftop agriculture enables urban areas to become more sustainable in their resource utilization and to assist residents in improving food security. While growing food on buildings is a key component of making cities more sustainable and habitable, green roofs are not the total solution for providing cities with food security. If local urbanized farming is to be part of the solution to boost food security in cities, green roofs will have to be used as a place to help increase and maintain food products. ${ }^{10}$

Most of Dhaka's rooftops are flat and ideal for greening as for now many architects and residents of apartments have taken measures to make their rooftop in Dhaka city green and accessible. Survey ${ }^{4}$ reveals that out of 500 households, only $12 \%$ of households are either in roofs or balconies with gardens; most of them are located in posh residential areas such as Gulshan $(25 \%)$. In the new context of Dhaka, i.e. Dhanmondi, Gulshan and Baridhara, most of the flat roofs are isolated, with no relation to the adjacent one. People rarely use roofs as space for security reasons, although some of them are designed for it. ${ }^{11}$

The character of rooftops is different from the new Dhaka in the context of old Dhaka. Although most of the old Dhaka is very dense and there is a lack of open spaces, people on the rooftop socialize. Here roof to roof connection and interaction is notable. Due to the subdivisions of the plot, distances between roofs are insignificant.

\section{Common Fruits and Vegetables Produced in Rooftops of Dhaka}

Around 60 fruit and vegetable varieties are manufactured in Bangladesh. It is not possible to produce all styles on the rooftop. Depending on individual household food preferences, availability of seed types that can be grown on the rooftop, weather, and soil quality, the types and mixes are selected in the region. Guava, Lemon, Papaya, Grapes, Green Chili, Pumpkin, Squash, Onion, Garlic, Coriander leaves, Tomato, Mushroom, Leafy vegetables (e.g., Callaloo, Jute Leaf and Red Amaranthus) and others (e.g., Cucumber, Flat Bean, Bitter ground, Ribbed ground, Ladies foot, Amaranthus, Dhudi, Cowpea, and Brinjal) are usually grown in the food garden. Some families also cultivate spices and plants used for medicinal purposes. ${ }^{12}$

A baseline survey was conducted from January to June 2016 with a sample of about 97 using a pre-tested semi-structured questionnaire for required data/information on rooftop gardening in Dhaka found that the average yield was higher for several specific vegetables and fruits (Figure 1). ${ }^{13}$

\section{Economic Benefits from Rooftop Gardening in Dhaka}

A baseline study on rooftop gardening in Dhaka stated that the gross return was obtained from all vegetables and fruits 


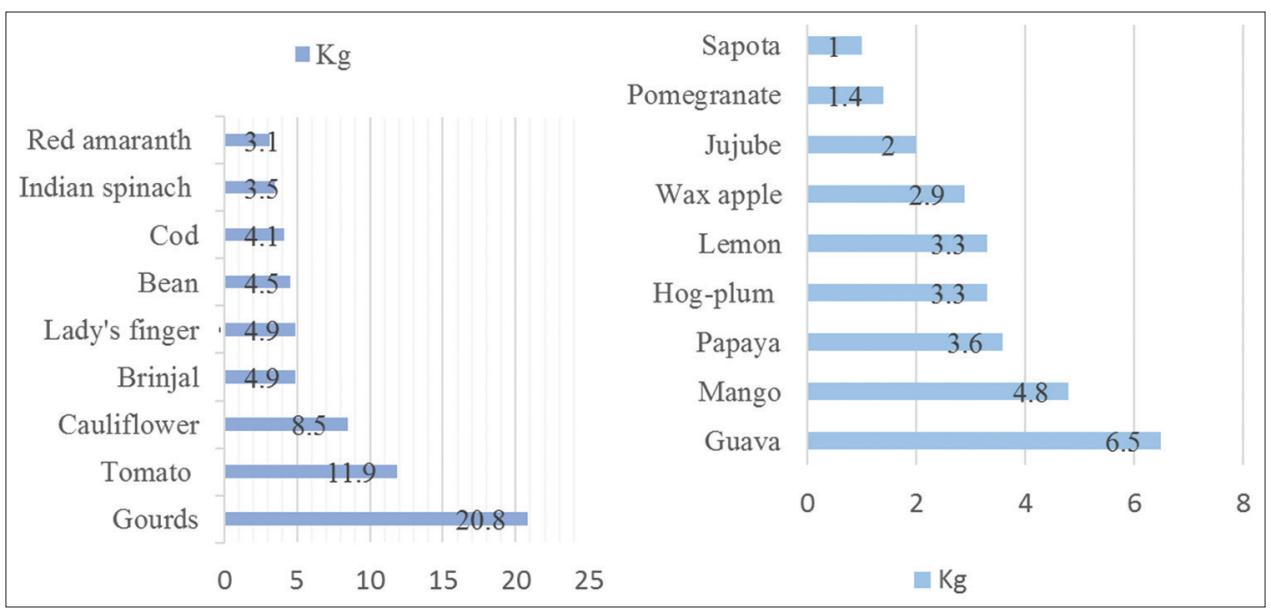

Figure 1: Average yield of vegetables and fruits on rooftops in Dhaka. ${ }^{13}$

produced in the current RTG's in Dhaka city areas as Tk. 2686 per year. The highest gross return came from fruits like Tk. 1486 and vegetables as Tk. $1200 .{ }^{13}$

A study conducted by M. Safayet et al. (2017) stated that the food production value from the rooftop farming of the practitioner of Mirpur area is estimated to be between Tk. $473,846.79$ and Tk. 4738,467.936 i.e. US\$ 6020 and US\$ 60202. As the garden mostly produces mixed fruits and vegetables, so the total value of production is likely to be at the lower end of this range (around Tk. 473,846.79 i.e. US\$ 6020). Again, the food production value from the rooftop farming of the practitioner of Mohammadpur area is estimated to be between Tk. 210,596.98 and Tk. 2,105,969.80 i.e. US\$ 2676 and US\$26756. As the garden produces fruits, vegetables and also lettuces, flowers, so the total value of production is likely to be in the middle of this range (around Tk. 1,158,283.39 i.e. US $\$ 14,716) .{ }^{14}$

Sajjaduzzaman (2005) reported that the purpose concerning financial gain from roof gardening is a very minor concern (4\% only) in Dhaka Metropolitan city of Bangladesh. ${ }^{4}$ On the other hand, Rumana Rashid et al., (2010) described the economic and social benefit of rooftop gardening including fresh food supply for urban residents, converts the hard surface into a soft green surface, energy saving, etc.). ${ }^{5}$

\section{Common Problems Faced by Practitioners in Dhaka}

There is an ambivalent relationship between birds and vegetables. Although many birds are important predators of pests in the garden, it has been found that birds often cause disturbance by eating small plants of vegetables and fruit. The plant leaves make the roof unclean so that the roof needs to be periodically washed. Another problem is finding plants of good quality. They get plants most of the time from a local nursery. But sometimes they get discouraged and buy low-quality crops, so they don't get desirable output. In 2013, only one-time assistance was provided from the Department of Agriculture Extension (DAE) project. There is no further support or follow-up to boost their rooftop farming from the state or any other organization. Tenants are typically not interested in garden development. In addition, a professional gardener would be needed if the practitioner wants to expand the garden. Another problem that has been found to hamper the development in her garden by the shadow of the neighboring building. Therefore, the absence of height and (building) density zoning would be a more potential issue if the number of such practitioners increased..$^{14}$

\section{Threats to Rooftop Farming in Dhaka}

It had been discussed during the study of non-practitioners why people did not practice rooftop farming. Most of them said they didn't have enough leisure or free time to introduce and take care of the garden. 33.3 percent of people said they were busy with their personal and official work and had insufficient time to spend on gardening or farming. Lack of technological knowledge also constitutes a constraint not to practice. There are very few ways to acquire knowledge of technology and agriculture. ${ }^{14}$

To train people and provide adequate farming equipment, there is no governmental or private initiative. But $25 \%$ of people say they don't want to learn because they don't have proper knowledge of agriculture.

There is also a desire to purchase food items instead of producing them from near-market places. Nineteen percent of people think that buying the required goods from nearby markets or kutcha bazar is easier than growing on their rooftops because time, labor and money are needed. So by spending some money, they feel they can have what they want. Manpower shortages are also a limitation. If people want to introduce farming on their rooftop, they need some support, but there is a shortage of experienced and skilled labor to take care of farming in the present condition. 15.5 percent of people believe that having no resources is a concern for them. Only $7.2 \%$ of people replied that they had insufficient space because their roof was used for other purposes. ${ }^{14}$

\section{RECOMMENDATIONS}

- There are no proper initiatives and incentives from the government or any other organizations to boost up and 
flourish the practice of rooftop farming in Dhaka city. As mentioned earlier, in Tokyo, Austin, and Portland, there are policy incentive activities. Similarly, many policy incentives can also be implemented for Dhaka city. However, in current building codes like the Bangladesh National Building Code (BNBC 2006), there was no provision for including facilities for rooftop farming when any building is designed.

- Therefore, the provision can be made in BNBC and can be enforced to make rooftop farming compulsory in all new buildings. Additionally, FAR (Floor Area Ratio) or density bonus can be given to people who will practice rooftop farming. This will further encourage the real estate sector to consider rooftop farming in the designing building. Moreover, the municipality should provide funds or incentives for those who are currently practicing and those who will practice in the future as by stormwater retention due to rooftop farming, the municipality can save a significant amount of money. Also, if the government provides incentives regarding the price of plants and necessary equipment, it may encourage people to initiate rooftop farming.

- There is a lack of information about rooftop farming among Dhaka city dwellers. People are not completely aware of the benefits of rooftop farming. This is mainly because that government, community and NGO side are not making coordinated efforts on it. Again, many people do not have sufficient technical or farming knowledge on rooftop farming.

- Proper training and awareness programs should be initiated by the Government to spread the knowledge of rooftop farming. DAE should be worked more efficiently and should be supportive to make provision of rooftop farming training regularly through support from NGOs or community organizations.

- Although most of Dhaka City's roofs are suitable for gardening, some modifications are always necessary to make it more suitable for rooftop farming. However, if the layout of a building considers rooftop farming from the initial phase so that it can bear the load of plants, soil, etc., this additional modification and additional costs are not required. It should also be planned that what plants to be grown and which space of the roof can bear how much of the weight, the size of the drums or tubs, etc. There should also be provided to provide necessary facilities like water taps in different locations on the roof, designated space for plantation, the facility of netting to protect plants and fruits from birds, etc. During the design phase of the houses, all these necessary measures should be considered.

- Roof dampness is one of the most prominent challenges facing rooftop farming in Dhaka. To save the roof from any harmful situation, drums, containers, and tubs can be put over the bricks. If there are bed systems for vegetables and fruit, the roof will be saved from future damage.

\section{CONCLUSION}

As the population of Dhaka city is growing higher and higher, the demand for food and expenditure on food is also increasing. But the resource is scarce as agricultural land is converting to residential, commercial or industrial land uses. It reduces the possibility of increasing more and more agricultural food products. Again food contamination such as harmful chemical usage to ripe fruits, hazardous or inorganic fertilizer and pesticide use to increase production, etc. In these circumstances, to solve these problems and find a way out, initiation of rooftop farming can be a possible and potential solution.

Rooftop farming can help to meet food demand by supplying fresh and hygienic food products, reducing household expenditure for buying vegetables and fruit, saving cost for the municipality by stormwater retention, creating a healthy atmosphere by improving air quality and absorbing carbon from the air and lessening the impact of climate change. But this is not possible to implement on a large scale without government provision. But other cities can also practice and may get similar benefits. Other countries that have a scarcity of cultivable land like Bangladesh can also practice rooftop farming to increase greenery and fresh food supply by following the farming method. Any further work such as measuring the benefits of rooftop farming in local, regional and national contexts, standardizing the constant factors of monetary valuation, developing a replicable rooftop farming model is possible with the help and guidance of this report.

\section{CONFLICT OF INTERESTS}

The authors declare that they have no competing interests.

\section{SOURCES OF FINANCIAL SUPPORT}

There is no funding to be disclosed.

\section{REFERENCES}

1. Hamm, M. W., \& Bellows, A. C. (2003). Community food security: background and future directions. Journal of Nutrition Education and Behavior, 35(1), 37-43.

2. Choguill, C.L.1995. Urban Agriculture and Cities in the Developing World, Habitat International, Vol. 19, No. 2 pp. 149-235.

3. Islam, Khandaker M. Shariful. (2004). Rooftop Gardening as a Strategy of Urban Agriculture for food security: The Case of Dhaka City, Bangladesh. Dept of Public Administration, The University of Dhaka, Bangladesh. Proc. IC on Urban Horticulture Eds: R. Junge-Berberovic et al. ActaHort 643, ISHS.

4. Sajjaduzzaman M. Koike MA, and Muhammed N. An Analytical Study oncultural and financial aspects of roof gardening in Dhaka metropolitan city of Bangladesh. Int J Agri Biol. 2005;7:184-7.

5. Rumana Rashid, Mohd. Hamdan Bin Ahmed, Md. Sayem Khan. (2010). Green Roof and Its Impact on Urban Environmental Sustainability: The Case in Bangladesh. World Journal of Management 2(2):59 - 69.

6. Mowla, Q. A. (2010, October). Green Roof Concept for EcoSustainability in the Context of Urban Dhaka. In the International seminar on "GO GREEN “, ACA-14 October (pp. 25-30).

7. NNC - National Nursery Consortium, 2007, "Plants for people and Society", Special publication for National Tree Fair 2007, NNC, Idea Printers, Dhaka.

8. Shadi, Shekh, 2007, "Chhad Bagan”, Dibya Prokash, Dhaka.

9. Samangooei, M.; Sassi, P.; Lack, A. Soil-less systems vs. soil-based systems for cultivating edible plants on buildings in relation to the contribution towards sustainable cities. Future Food J. Food Agric. Soc. 2016, 4, 24-39.

10. Walters, S., \& Stoelzle Midden, K. (2018). Sustainability of Urban Agriculture: Vegetable Production on Green Roofs. Agriculture, 8(11), 168.

11. Hossain, M. M. 2009, Effects of Green Roof Concept on Residential 
Apartment Buildings in the Context of Dhaka City, unpublished M.Arch term paper under the supervision of Prof. Dr. Qazi A. Mowla (the author of this paper) of Bangladesh University of Engineering and Technology, Dhaka.

12. Shariful Islam KM. Rooftop gardening as a strategy of urban agriculture for food security: The case of Dhaka City, Bangladesh. International Conference on Urban Horticulture 6432002 Sep 2 (pp. 241-247).

13. Uddin, M. J., Khondaker, N. A., Das, A. K., Hossain, M. E., Masud, A. D. H., Chakma, A. S., ... \& Chowdhury, A. A. (2016). Baseline Study on
Roof Top Gardening in Dhaka and Chittagong City of Bangladesh (Vol. 8, p. 4). A final technical report under the project of "Enhancing Urban Horticulture Production to Improve Food and Nutrition Security"(TCP/ BGD/3503) funded by Food and Agriculture Organization of the United Nations. FAO Representation in Bangladesh. Road.

14. Safayet, M., Arefin, M. F., \& Hasan, M. M. U. (2017). Present practice and future prospect of rooftop farming in Dhaka city: A step towards urban sustainability. Journal of Urban Management, 6(2), 56-65. 